\title{
The Development Trends in Drug Rehabilitation in China's Judicial Administration Department
}

\author{
Dongming Jia1,2, Zuzhen Jiang², Yang Zhang1, Jing Wang1, Yufei Zhou' ${ }^{1}$, Liji Ma1', Song Guo ${ }^{3}$ \\ ${ }^{1}$ Department of Criminal Justice, Zhejiang Police Vocational Academy, Hangzhou, China \\ ${ }^{2}$ Drug Detoxification and Rehabilitation Research Center of The Central Institute for Correctional Police, Baoding, China \\ ${ }^{3}$ Department of Education and Correction, Zhejiang Gongchen Compulsory Isolated Detoxification Center, Hangzhou, China \\ Email: *jiadm1@126.com
}

How to cite this paper: Jia, D. M., Jiang, Z. Z., Zhang, Y., Wang, J., Zhou, Y. F., Ma, L. J., \& Guo, S. (2019). The Development Trends in Drug Rehabilitation in China's Judicial Administration Department. Beijing Law Review, 10, 239-245.

https://doi.org/10.4236/blr.2019.101014

Received: February 21, 2019

Accepted: March 22, 2019

Published: March 25, 2019

Copyright $(\odot 2019$ by author(s) and Scientific Research Publishing Inc. This work is licensed under the Creative Commons Attribution International License (CC BY 4.0).

http://creativecommons.org/licenses/by/4.0/

\begin{abstract}
Aim: To review the recent progress of drug rehabilitation in China's judicial administration department and put forward suggestions. Method: We introduced general objective for rehabilitation work, the composition and operation of the unified " 451 mode" in the whole country and new advanced treatment methods.
\end{abstract}

\section{Keywords}

Drug Rehabilitation, Judicial Administration Department, China

\section{Introduction}

According to the Anti-drug Law of the People's Republic of China and the Drug Rehabilitation Regulations, the judicial administration department of the State Council undertakes the functions of compulsory isolated detoxification, drug rehabilitation administration and the guidance and support for detoxification and rehabilitation in the community.

In May 2018, Chinese Ministry of Justice convoked a national judicial administration drug rehabilitation conference in Hefei, Anhui Province. China will establish a unified national judicial administration drug rehabilitation operation mode (451 model) based on the four phases and wards, five major professional centers and one extension of social assistance in $2-3$ years.

Drug rehabilitation in Chinese judicial administration department originated in abolition of reeducation through labor system in 2013. At present, there are 361 compulsory isolated detoxification centers in the country, with an admitted 
addicts' capacity of 320 thousand. More than $1.3 \mathrm{~m}$ addicts have been treated, and now there are nearly 240 thousand in these centers. In addition, 73 rehabilitation centers (regions) are still working for treating nearly 6000 addicts $(\mathrm{Wu}$, 2018).

The focus of drug rehabilitation is on specialized medical treatment, education and correction and rehabilitation training. Now there are 57 thousand policemen in the whole system, including nearly 5000 medical professionals, 10,000 counselors at or above level three, more than 10,000 full-time and part-time teachers and nearly 4000 rehabilitation training instructors. Professional teams provide strong talent support for judicial administration.

It is worth mentioning that the legitimate rights and interests of drug addicts are effectively protected. Good accommodation, learning and working environment are provided, hygiene and basic nutritional needs in the diet are gratified. Respecting the personality and dignity of drug addicts, resolutely puts an end to all forms of abusing and degrading dignity and protects the safety and health of the addicts. Drug addicts participating in production can obtain labor protection supplies and corresponding labor remuneration. Overtime physical labor is strictly prohibited, and the rights and interests of female and minor addicts are well protected. Female addicts are directly managed by female policemen, juvenile addicts are under unified management in juvenile compulsory isolation centers, which help them complete nine-year compulsory education (Jiang \& Zhang, 2018).

Furthermore, "Regulations on Compulsory Isolation and Drug Rehabilitation by Judicial Administrative Department", "Measures for Diagnosis and Evaluation of Compulsory Isolation and Drug Rehabilitation" and "Basic Standards for Drug Rehabilitation Work in Judicial Administration" were promulgated successively, which involved the behavioral norms, education correction, management, hygiene, publicity and security. A relatively complete system of drug rehabilitation in China's judicial administration department with Chinese characteristics has been basically established.

\section{Advantages of Compulsory Isolated Detoxification Work}

As the main component, compulsory isolated detoxification work has played a huge role. One is to offer non-toxic treatment environment for drug addicts. Compulsive means can improve self-control and get rid of drug dependence under isolated conditions. Furthermore, modern means were applied for drug addicts to provide a full chain, systematic and professional comprehensive treatment, so that the cognitive ability of drug resistance, mental health and social adaptability will get comprehensive rehabilitation (Huang, 2018). Last but not least, this work has reduced drug-related crime and social problems such as AIDS transmission from the source, meanwhile, drug consumption market a certain shrunk. In practice, compulsory isolated detoxification work has been widely recognized by the whole society, drug addicts and their families. 


\section{Unified National Drug Rehabilitation Operation Mode (451 Mode)}

China's drug rehabilitation work has a general objective and "451 mode" to improve the abstinence rate and reduce the relapse rate of the drugs.

\subsection{General Objective for Rehabilitation Work}

The overall goal is to propose that the physical detoxification rate, rehabilitation treatment rate, and the community convergence rate should reach up to $100 \%$, equally, standard-reaching rate of physical fitness test, improvement rate of cognitive function, diagnostic qualification rate and the rate of family intervention more than $90 \%$ (An, 2018).

\subsection{The "451 Mode"}

The "451 Mode" means "Four phases and wards, five major professional centers and one extension of social assistance". It include: 4 means four phases and wards: 1) physiological detoxification ward; 2) educational adjustment ward; 3) consolidation ward; 4) reintegration guidance ward. 5 means five major professional centers: 1) medical rehabilitation centre; 2) mental rectification center; 3) rehabilitation training center; 4) education correction center; 5) Diagnostic assessment center. The last 1 means the extension of social assistance. The "451 Mode" operation process is shown in Figure 1.

\section{Review of Advanced Treatment Methods}

China has been innovating various scientific methods in the drug rehabilitation field of judicial administration department. A brief account is as follows.

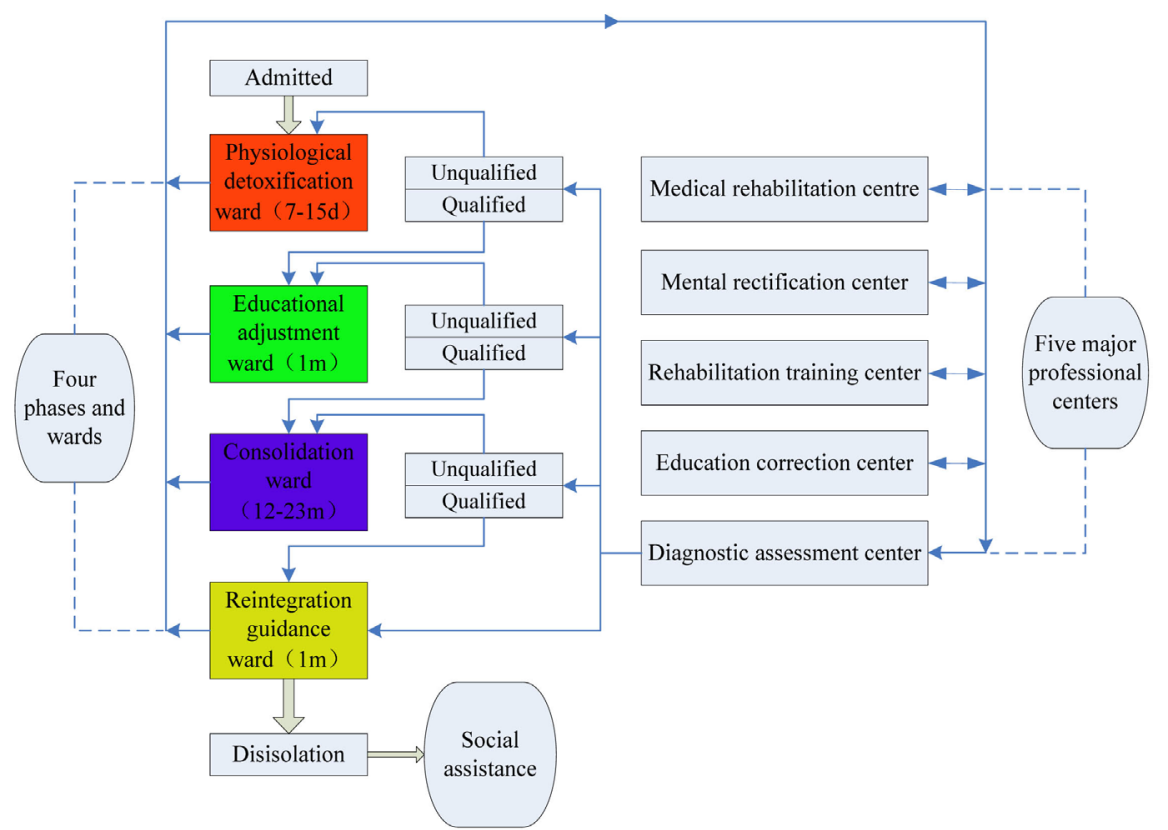

Figure 1. Flowchart of "451 Mode". 
Virtual Reality (VR): The VR technology was using to eliminate pathological drug addiction memory through eye tracking technology, physiological parameter detection and quantitative assessment in Shanghai. They were also providing the aversion treatment, desensitization treatment and social rehabilitation services. At present, a comparative analysis in Zhejiang Province proved that the accuracy of prediction of methamphetamine craving is $95.9 \%$, and $t$ effective rate and cure rate are $37.6 \%$ and $73.6 \%$ respectively (Xie, 2018).

Repetitive Transcranial Magnetic Stimulation (rTMS): The rTMS can regulate brain function and nerve circuits, and achieve accurate stimulation of brain-related parts (targets). Its mechanism is related to regulating excitability of cerebral cortex, synaptic structure and neuronal plasticity, some brain regions and functional connection of different brain regions, so as to achieve the goal of precise detoxification (Liang, Lin, \& Yang, 2018).

A one-year follow-up by 80 drug addicts in GaoJing center showed that the behavior of drug addicts after treatment improved significantly, and the rate of violation of discipline in the experimental group was only $48 \%$ contrast with that in the control group. Practice has proved that drug addicts who have received rTMS therapy have been significantly improved in terms of drug craving, sleep disorders, impulsive reduction, and self-adjustment.

Mindfulness Recurrence Prevention Training Program: This project is a special method of concentration, including yoga, breathing, physical exercise, skill training, and homework designed specifically for drug users. It can improve the psychological quality of drug addicts, make the appropriate choice of drugs and environment, and reduce the possibility of recurrence (Ma, 2018). Through training, the cognitive ability, self-awareness ability and positive emotional response of drug addicts were improved, the negative emotional response was decreased, and the degree of craving showed a downward trend.

Naikan Therapy: Naikan therapy is a kind of psychotherapy that observes one's heart and recognizes oneself. By recalling the basic interpersonal relationships in one's life experience, the insider examines three items: 1 ) what others have done for me; 2) what I have done for others; 3) what has caused trouble to others. By reviewing and evaluating ourselves, we can correct unhealthy attitudes and improve personality characteristics.

The drug addicts who have received insight detoxification performed better than those in the control group in terms of compliance and discipline, productivity and labor efficiency, and their integrity retention rate was significantly higher than that in the control group (Su, 2018).

Systematic Desensitization Therapy Based on Biofeedback Technology: "Systemic desensitization" is a psychotherapy technology, which utilizes the principle of interaction inhibition (conditioned reflex) and regression to establish a hierarchical level and train gradually and repeatedly. Combining with biofeedback techniques, it puts unconscious physiological activities under the control of consciousness and forms fixed, random and controllable behavior after repeated training, which ultimately improves brain nerve activity, helps them get rid of 
bad emotions, relieve psychological stress and quit drugs (Zou, 2018).

Exercise-assisted Rehabilitation: The project uses self-developed "gait balance training instrument", "taiji rehabilitation exercise", "fancy rope skipping" and other sports to enhance self-control ability and stimulate brain reward loop, and improve endogenous motivation for drug detoxification (Jia, Xu, Guo, \& Shen, 2018). The follow-up data of 80 female addicts who participated in the experiment in 2017 showed that the two-year relapse rate was only half of those who received regular education, and the effect of drug treatment was very obvious (Chen, Chen, \& Xu, 2018).

Modular Hierarchical Education Curriculum System Project: This project takes "being a priority for precautions, facing the society and educating people as a whole" as a threshold to design a modular and hierarchical system framework, and build a scientific and dynamic curriculum structure. We have developed a series of "virtual reality" training courses to enhance the ability of the addicts to refuse drugs by setting up high-risk situations and carrying out cognitive behavioral therapy. Modular design of the curriculum system, including different modules corresponding to the analogous educational objectives, to ensure continuity and pertinence of the curriculum, to avoid repetitive teaching (Long, $\mathrm{Fu}, \& \mathrm{Guo}, 2015)$. Hierarchical design refers to the hierarchical design of some courses according to the difficulty level of course content and the logical order of subject knowledge, in order to better respond to the different needs of education and correction for the addicts.

\section{Discussion}

China is in the midst of contagion of the drug problem, a high incidence of drug-related crimes and a concentration of drug control. The number of the addicts in judicial and administrative places is increasing, the composition of personnel is complex, the difficulty of education is increasing, and the task is arduous. In recent years, with the accelerated spread of new synthetic drugs, the number of drug addicts admitted to compulsory isolation drug treatment places by judicial administration is also increasing year by year (Jia, Guo, \& Yu, 2018). According to statistics, the number of drug users who take new synthetic drugs has accounted for $53 \%$ of the total number. In some places, the ratio is even higher, reaching $80 \%$ and $90 \%$.And China has added 32 designer drugs to its list of controlled substances. The latest batch of new psychoactive substances, or NPS, added to the list includes 4-CEC and 4-EMC. NPS are stronger than traditional narcotics, such as heroin or methamphetamine, and have caused serious problems for society, So far, 170 kinds of NPS have been listed as controlled substances, according to the ministry. Since last year, police have uncovered seven cases involving such substances and detained 53 suspects (Wei \& Zhou, 2018).

\section{Conclusion}

China adheres to the principle of "people-oriented, scientific rehabilitation, 
comprehensive correction, care and relief", with improving the quality of education and treatment as center, and takes increasing the withdrawal rate and reducing relapse rate as the starting point and foothold. We insisted on scientific and professional development and achieved a series of fruitful results, formed a judicial administration drug rehabilitation working system with Chinese characteristics. It is not long before China's judicial system has been transformed from Reeducation-through-labor to drug rehabilitation (Liu, Liang, \& Zhao, 2018). The situation of simply copying the original management practices and experience has not been completely eliminated. Specialized teams and facilities needed to adapt to drug rehabilitation work have not been fully established. The concept, methods and institutional mechanisms for drug rehabilitation need to be further transformed and explored. The next direction is "Intelligent Rehabilitation" by applying big data and information technology.

\section{Acknowledgements}

The authors thank the members of the Zhejiang Police Vocational Academy and Zhejiang Gongchen Compulsory Isolated Detoxification Center who made this project possible. This project was supported by grants from the Science and Technology Innovation Plan for University Students in Zhejiang Province.

\section{Conflicts of Interest}

The authors declare no conflicts of interest regarding the publication of this paper.

\section{References}

An, J. (2018). Establishing a Unified Basic Model of Drug Rehabilitation to Promote Innovative Development of Judicial Administration of Drug Rehabilitation. China Judiciary, No. 9, 75-78.

Chen, W., Chen, Y., Xu, Y. et al. (2018). Effects of Physical Rehabilitation Training on Physical Health Indicators of Female Drug Addicts. Sports Science and Technology, No. 5, 33-35.

Huang, X. (2018). Trends and Countermeasures of Community Drug Rehabilitation in China. Health Care Guidelines, No. 44, 366.

Jia, D., Guo, S., Yu, Z. et al. (2018). Designer Drugs: Overview, Pharmacology and Clinical Issues. Chinese Journal of Drug Abuse Prevention and Control, 24, 57-62.

Jia, D., Xu, Z., Guo, S., \& Shen, Y. (2018) Practical Research on Physical Rehabilitation Training among Male Addicts in Chinese Compulsory Isolated Detoxification Center. Open Journal of Preventive Medicine, 8, 121-130. https://doi.org/10.4236/ojpm.2018.84012

Jiang, Z., \& Zhang, K. (2018). Construction and Operation of the Basic Mode of Judicial Administration for Drug Rehabilitation. People's Rule of Law, No. 22, 21-27.

Liang, Q., Lin, J., Yang, J., et al. (2018). Intervention Effect of Repetitive TMS on Behavioral Adjustment after Error Commission in Long-Term Methamphetamine Addicts: Evidence From a Two-Choice Oddball Task. Neuroscience Bulletin, 34, 449-456. https://doi.org/10.1007/s12264-018-0205-y

Liu, Y., Liang, J., Zhao, C., et al. (2010). Looking for a Solution for Drug Addiction in 
China: Exploring the Challenges and Opportunities in the Way of China's New Drug Control Law. International Journal of Drug Policy, 21, 149-154.

Long, G., Fu, J., \& Guo, Q. (2015).Reflections on the Construction of the Education System for Compulsory Isolation of Drug Addicts. China Judiciary, No. 8.

Ma, Y. (2018). Promotive Study of Mindfulness Intervention on Interpersonal Relations of Drug Addicts. Psychologist, 24, 314-315.

$\mathrm{Su}$, J. (2018). Application of Positive Psychology in Rehabilitation from Drug Abuse. Chinese Journal of Drug Abuse Prevention and Control, 24, 282-285.

Wei, Y., \& Zhou, B. (2018). Current Situation and Relevant Countermeasures of Psychoactive Substance Dependence Therapy in China. Research and Practice of Health Care Medicine, 15, 91-96.

Wu, A. P. (2018). Analysis of the Current Situation of Law Enforcement Standardization Construction in Compulsory Isolation Drug Treatment Places and Preliminary Countermeasures. Legal System and Society, No. 27, 175-176.

Xie, Y. (2018). Exploration of the Application of Aversion Therapy Combined with Virtual Reality Technology in Drug Treatment. Journal of Yunnan Police College, No. 3, 7-10.

Zou, W. (2018). Study on Anxiety Level in Systematic Desensitization Treatment of Compulsory Isolation Drug Addicts. Journal of Anhui Police Vocational College, 17, 16-18. 